\title{
Factor for Toxicological Dose Descriptor
}

National Cancer Institute

\section{Source}

National Cancer Institute. Factor for Toxicological Dose Descriptor. NCI Thesaurus.

Code C158373.

The quantity given for the multiplier of the toxicological dose descriptor 